\title{
Facilitated modelling in strategy development: measuring the impact on communication, consensus and commitment
}

\author{
EAJA Rouwette* \\ Radboud University Nijmegen, The Netherlands
}

Facilitated modelling is used in supporting the resolution of strategic issues mainly because it is expected to improve communication between decision makers, foster consensus and create commitment. Researchers in both the strategy and facilitated modelling fields call for more systematic research on how strategy development works in practice and how outcomes are created. In this paper, three facilitated modelling cases on strategic issues are studied using both written questionnaires, developed in the strategy and decision support fields, and semi-structured interviews. Results of both measurement approaches are compared to determine (a) to what extent outcomes in participants' own terms are similar to concepts in the questionnaire and (b) whether changes measured by both methods are similar. Interview results are used to assess (c) which elements of the intervention contribute to outcomes. Findings suggest that questionnaires offer clear benefits as standardized measurement of facilitated modelling outcomes.

Journal of the Operational Research Society advance online publication, 21 July 2010

doi: $10.1057 /$ jors. 2010.78

Keywords: problem structuring methods; facilitation; system dynamics; evaluation

\section{Introduction}

Problem Structuring Methods (PSMs) are a collection of methods that assist a group of stakeholders in gaining a joint understanding of a problematic situation (Rosenhead and Mingers, 2001; Mingers and Rosenhead, 2004). PSMs facilitate stakeholders in the process of developing a model of their problematic situation and agreeing on possible improvements. Well-known examples of PSMs are soft systems methodology (Checkland, 2000), the strategic choice approach (Friend and Hickling, 1987; Friend, 2001), and strategic options development and analysis (Ackermann et al, 2005). Although the original set of PSMs is developed in the UK, there are a couple of methods that are seen as closely related as they also use models and facilitation in structuring complex problematic situations. Among these other facilitated modelling approaches are strategic assumptions surfacing and testing (Mason and Mitroff, 1981) and group model building (Vennix, 1996; Andersen et al, 2007).

Facilitated modelling approaches are typically used in unstructured problem situations that touch on the interests

\footnotetext{
${ }^{*}$ Correspondence: EAJA Rouwette, Methodology Department, Faculty of Management, Radboud University Nijmegen, Thomas van Aquinostraat 1.2.31, PO Box 9108, 6500 HK Nijmegen, The Netherlands.

E-mail: E.Rouwette@fm.ru.nl
}

of diverse and often autonomous stakeholders, each with their own perspectives. The issues entail uncertainty and potential conflict between stakeholders and may have wide implications across the organization(s) involved (Rosenhead, 1996). This type of situation shares many characteristics with strategic decisions, in which the direction of the organization is set or adjusted and major resources are committed (Eisenhardt and Zbaracki, 1997; Sanchez and Heene, 2004). Not surprisingly, several facilitated modelling approaches explicitly target strategic problems (Eden and Ackermann, 1998; Warren, 2008; Gary et al, 2009).

The strategy and facilitated modelling fields share an interest in how strategy is done in practice. Starting from classic contributions by authors such as Mintzberg (1994), the strategy-as-practice field is the most recent area of strategic research, which concerns itself with human actors and their involvement in the process of strategy (Jarzabkowski and Spee, 2009). Among the most relevant subjects for future studies, Jarzabkowski and Spee (2009, p 91) identify technologies for strategy making, detailed analysis of how what strategists do constructs particular outcomes and explanations of variations in outcomes. Facilitated modelling is a particular type of technology aimed at specific outcomes. Where traditional OR methods contribute to strategy development by their emphasis on 
substantive rationality, facilitated modelling may also increase procedural rationality (Eden, 1989; Pidd, 2004). Process-related outcomes, such as quality of communication, consensus and commitment, are central concepts in many reports on applications of facilitated modelling (Rouwette et al, 2009).

The state of the research on facilitated modelling can aptly be described using McGrath's (1982) metaphor of the research process as a three-horned dilemma. All research would like to maximize three outcomes: generalizability with regard to populations, precision in control and measurement of variables, and realism for participants. However, maximizing any of these will reduce the score on the other two. Research on facilitated modelling has clearly optimized realism and sat down squarely on the other two horns. Most facilitated modelling methods originated in the 1970s. Typically, the inventors of the methods developed their approach further on the basis of real-life projects with paying clients. Development of methods was not driven by systematic evaluation. Evidence for the effectiveness of methods is often anecdotal (Westcombe et al, 2006). Although reviews on the effects of approaches are beginning to appear (Mingers, 2000; Rouwette et al, 2002; Mingers and Rosenhead, 2004), fundamental assumptions underlying methods are not tested. This leads to two contrasting descriptions of the current state of the field of facilitated modelling. On the one hand, by looking at the number of published case reports one might easily conclude that facilitated modelling approaches are successful. On the other hand, when looking at the nature of this evidence for effectiveness of methods, there is little reason for satisfaction. Generalizability and precision are lacking in research on facilitated methods. In particular the lack of precision has received attention from researchers in the field of modelling. Ideally success in applied cases is a result of the method used, but it might also be the effect of the facilitator (Eden, 1995), the fact that stakeholders are brought together, mere attention (the Hawthorne effect) or a number of other factors (see Rouwette and Vennix, 2007 for alternative hypotheses). The facilitated modelling field has been criticized because of its lack of clarity on which elements of the approach contribute to effects (Eden, 1995; Finlay, 1998). For instance, if the facilitator is responsible for most of the observed effects, can we still speak about a methodology? There is clearly a role for a more systematic assessment of the outcome of interventions (Eden and Ackermann, 2006; Westcombe et al, 2006; Andersen et al, 2007).

A systematic assessment of outcomes is difficult for a number of reasons. First, the outcome of any intervention will depend both on a large number of variables in the context and the intervention (mechanism) itself. For instance, since we assume that facilitated approaches depend on the information exchanged in sessions, results will differ among settings in which goals of stakeholders overlap and those that are highly politicized and in which participants have hidden agendas. Pawson and Tilley (1997) argue that a realistic comparison of evaluation studies boils down to discovering which combinations of mechanism and context lead to which outcomes. Mechanism in this sense refers to the causal factors in the intervention process that bring about desired outcomes. Vennix (1996) for example assumes that facilitated modelling supports the limited information processing abilities of human decision makers. In Vennix's view, information processing ability is thus an important mechanism variable that is effective in the creation of desired outcomes of facilitated modelling. Determining which of the variables in the context, mechanism and outcome are relevant, is only possible on the basis of a theoretical framework. Eden (1995) maintains that any evaluation of facilitated modelling interventions should be based on a clear theoretical framework. Although each method follows a particular process and aims for specific outcomes, communication, consensus and commitment are central concepts in all facilitated modelling interventions (Morton et al, 2003; Rouwette et al, 2009).

When it is clear which elements in context, mechanism and outcome will be focused upon, a decision needs to be made on how to operationalize and measure these concepts. Data on context and mechanism variables are commonly found in project notes and session observations. For the assessment of outcomes of interventions a number of alternatives are available. Qualitative assessments seem to be more popular than quantitative assessments. Out of 107 case reports reviewed by Rouwette et al (2002), 88 can be described as qualitative case studies. All of these use observation and a minority use interviews for assessing outcomes. The remainder of the cases (19 studies) use some form of quantitative assessment of results, typically in the form of a written questionnaire. Facilitated modelling involves gathering in-depth information on the issue at hand, and a case study may be a natural extension of this type of intervention. Eden sees serious shortcomings in using questionnaires to assess outcomes, observing that participants are unwilling to participate in answering questions (Eden, 1995) and that in-depth interviews sometimes put questionnaire results in an entirely new light (Eden, 2000). It seems useful to assess the similarity between concepts as understood by participants (from the perspective of the insider) and concepts as defined by researchers (from the perspective of an outsider). Poole and Folger (1981) make a similar argument with regard to interaction coding schemes.

A number of arguments against relying exclusively on qualitative measures can be made as well. First, a potential benefit of using questionnaires is the fact that outcomes are measured in a similar way across studies. Rouwette et al (2002) find that outcomes such as consensus and commitment are operationalized and measured in different ways, 
making accumulation of results difficult. A more systematic assessment of the results of interventions seems impossible without a uniform way of assessing central concepts. As single facilitated modelling cases involve only a limited number of participants (typically between five and 12), we need to combine multiple cases in order to build up a database of results that allows for statistical testing of relations. Second, research by Nisbett and Wilson (Nisbett and Wilson, 1977; Wilson, 2002) shows that people have little insight into whether they have learned, and if so, what were the causes. Outcomes such as consensus and commitment involve cognitive and emotional change, similar to learning. Eden and Ackermann (1998) refer to an emotional and cognitive side of commitment. We might therefore argue that people will also have limited insight into the causes of changes in consensus and commitment. By measuring both the outcomes and the degree to which (hypothesized) triggers for creation of outcomes were present, we are better able to test expectations on how methods bring about expected changes.

In conclusion, research on facilitated modelling may benefit from more appropriate precision. In order to achieve this, it is necessary to be clear on which variables in the context, mechanism and outcome of interventions are relevant. Precision of measurement of outcomes may be increased by using standardized questionnaires, but there are doubts on whether these instruments accurately capture participants' ideas. The remainder of this paper explores the potential of questionnaires for more precise measurement of facilitated modelling interventions. The next section describes expected relations between the intervention and major outcomes (communication, consensus and commitment). Three cases studies are then described in which outcomes are assessed by using semi-structured interviews and questionnaires (for the same respondents). Results of both measurement approaches are compared to determine (a) to what extent outcomes in participants' own terms, are similar to dimensions in the questionnaire and (b) whether changes measured by both methods are similar. Interview results are used to assess (c) which elements of the intervention contribute to communication, consensus and commitment.

\section{Expected impacts on communication, consensus and commitment}

Although communication, consensus and commitment are central outcomes of facilitated modelling interventions, the literature in the field does not offer agreed-upon definitions of these outcomes. The concepts are multi-dimensional and overlap to some extent (Rouwette et al, 2002). For instance, commitment is one of the five dimensions by which DeStephen and Hirokawa (1988) measure consensus. In this section, concepts are first described in more detail. We then turn to the question how facilitated modelling influences communication, consensus and commitment. The purpose of this paper is not to develop a comprehensive conceptual model, but to isolate the relation between the intervention and each of three main outcomes (communication, consensus and commitment) and analyse each relation in more depth. General frameworks have been described elsewhere (Richardson et al, 1994; Rouwette and Vennix, 2007; Rouwette et al, 2009).

\section{Communication}

Akkermans and Vennix (1997, p 6) define communication in this context as the quality of the conversational process between the various participants. In their view, communication has the following dimensions: (a) exchange of ideas/ viewpoints: the degree to which participants feel they are able to present their ideas; (b) openness: the degree to which discussions are felt to be open (participants feel free to raise subjects for discussion); (c) common language: the degree to which a shared language is used; (d) (lack of) verbal dominance: the degree to which participants are able to contribute equally to the discussions; (e) freedom: the degree to which participants feel free to introduce their ideas and opinions. Facilitated modelling may improve communication via two paths: (a) communicative exchanges are more comprehensible, sincere, legitimate and accurate (Franco, 2006); (b) ability to process information is improved, allowing participants to focus more on the arguments (content) exchanged in the conversation (Rouwette et al, 2009).

\section{Consensus}

Consensus is a central concept in strategic management. In general terms, consensus refers to agreement on content or actions between a group of people. Whereas DeStephen and Hirokawa (1988) include actions as part of their definition of consensus, other definitons (Markóczy, 2001; Kellermanns et al, 2005) focus only on beliefs. We use the latter definition here. Markóczy (2001) distinguishes among four aspects of consensus: (a) locus: where in the organization the consensus is located, (b) scope: the persons who share in the consensus; (c) degree: how strongly the people involved agree on the content; (d) content: the actual beliefs that people agree on. Facilitated modelling may improve consensus via two paths: (a) participants' opinions converge as they exchange arguments for their respective positions (Rouwette et al, 2009); (b) the model constructed acts as a transitional object, which helps in translating one's own ideas to others (Eden and Ackerman, 2004). Checkland (1989) also refers to the potential of facilitated modelling to create an accommodation of interests. This dimension refers to agreement on values, which is different to agreement on beliefs. Therefore 
we do not include this dimension or path in our description of consensus.

\section{Commitment}

Commitment may alternatively refer to a course of action or to (part of) an organization. As the participants in the cases (described below) are not directly implementing the study's conclusions, the second alternative is used here. In an influential study, Mowday et al (1979, p 226) define organizational commitment as the relative strength of an individual's identification with and involvement in a particular organization. Dooley et al (2000) adapt Mowday et $a l$ 's definition to operationalize commitment of members of strategic decision-making teams. Commitment has three dimensions: (a) a strong belief and acceptance of the decision-making team's goals and values; (b) a willingness to exert considerable effort on behalf of the team; (c) a strong desire to maintain membership of the team. Facilitated modelling may improve commitment in two ways: (a) participants co-construct and achieve ownership over results (Akkermans and Vennix, 1997; Franco, 2007); (b) the procedure via which results are achieved is perceived as fair (Eden, 1992; Korsgaard et al, 1995).

\section{Context and mechanism of cases}

The relations of communication, consensus and commitment to elements of facilitated modelling were studied in three cases. All cases involve addressing strategic problems in government agencies in the Netherlands in a multiorganizational setting. At present, few studies on facilitated modelling involving multiple organizations are available (but see Franco, 2007). The cases play out at a strategic level, as indicated by the substantial investment of resources and the major adjustments of directions implied in the decisions. The first case concerns the recruitment of 500 additional criminal investigators and its impact on the Dutch National Forensic Institute and partner organizations. The second case concerns draft legislation, presented to the Dutch parliament, on conditional release of prisoners. The purpose of the proposed law is to reduce the chance of recidivism by making release of prisoners dependent on particular conditions. The third case started as a result of an increase in the occurrence of identification fraud in the administration of criminal justice. The Ministries of Justice and Internal Affairs developed a protocol for the determination of identity in order to ensure a proper identification of suspects and convicts, which would require a major investment in time in particular by the police force. In all cases, quantitative system dynamics models were constructed on the basis of interviews, plenary sessions and meetings in smaller committees. The modellers and facilitators in this case were from
Significant, a Dutch consultancy. The projects followed the guidelines on group model building (Vennix, 1996). In brief, these guidelines come down to the following. First, identify (preferably with the contact client, before the first group session) a dynamic problem of interest. Second, in a series of plenary sessions build a conceptual model of the structure responsible for this behaviour. Third, formalize model parameters and simulate the model. In this step participants are involved as much as possible, although a large part of the work on formalization and preparation of runs is done by modellers. Fourth, the model and runs are presented in a final session and described in a report, after which the model is handed over to the contact client. In the three cases, these guidelines were followed, with the exception that not all work was completed in the plenary sessions. Model structure and data that were the expertise of one or a few participants were discussed in a subgroup before they were addressed in a plenary session. Between nine and 11 participants were present in each session (see Table 1, in the table 'interviewed' refers to evaluation interviews after the project). All participants worked at senior levels in their respective organizations. Vennix (1996) proposes to use preliminary models, small conceptual models that participants may criticize and add to, in order to capture available knowledge and focus the first session. Preliminary models were used in the first and second project. In terms of Rouwette et al (2002), the first and third case resulted in models of medium size (between 50 and 200 equations), while the model built in the second case is small (with a maximum of 50 equations).

\section{Methodology}

The outcomes of each case were assessed on the basis of written questionnaires and semi-structured interviews. The final questionnaire and interview topic list can be obtained from the author. A total of 21 participants (seven in the first case, eight in the second and six in the third) completed the questionnaires in this study. For judging the quality of the scales for communication, consensus and commitment, scale reliabilities in published work and data from this study are used. Items with correlations below 0.20 to the rest of the scale are removed. Typically a scale reliability below 0.60 indicates low internal consistency (Malhotra and Birks, 2000, p 307). However, based on the limited number of respondents in this study, consistencies of 0.55 are accepted. All items are measured on a five point Likert scale anchored by strongly disagree-strongly agree.

For communication, a three-item scale originally developed by Vennix et al (1993) was used. The items covered understanding of the opinions of others, degree to which the model clarified communication and domination of discussion. Scale reliability using Cronbach's alpha in a 
Table 1 Context and mechanism elements of three cases

\begin{tabular}{llll}
\hline & Forensic investigation & Conditional release of prisoners & ID-protocol \\
\hline Organizations & 6: Police, Ministry of Justice, & 6: Central Justice Collection bureau, & 7: Central Justice Collection \\
involved & Ministry of Internal Affairs, & Service Judicial Institutes, Ministry & bureau, Service Judicial Institutes, \\
& Department of Public Prosecution, & of Justice, Department of Public & Ministry of Internal Affairs, \\
& National Forensic Institute, Service & Prosecution, Council of Justice, & Ministry of Justice, Department of \\
& National Investigation Information & 3RO (probation) & Public Prosecution, Council of \\
& & & Justice, 3RO (probation)
\end{tabular}

$\begin{array}{llll}\begin{array}{l}\text { Number of } \\ \text { participants } \\ \text { (interviewed) }\end{array} & 9(7) & 19(8) & 11(4) \\ \text { Methods } & \begin{array}{l}\text { Interviews, four plenary sessions, } \\ \text { bilateral sessions }\end{array} & \begin{array}{l}\text { Interviews, five plenary sessions, } \\ 11 \text { bi/trilateral sessions }\end{array} & \begin{array}{l}\text { Interviews, five plenary sessions, } \\ 18 \text { bilateral sessions }\end{array} \\ \text { Time span } & 5 \text { months, 2005-2006 } & 8 \text { months, 2006-2007 } & 11 \text { months, 2007-2008 } \\ \text { Size model } & 100-200 \text { variables } & <50 \text { variables } & 50-100 \text { variables } \\ \begin{array}{l}\text { Preliminary } \\ \text { model }\end{array} & \text { Yes } & \text { Yes } & \text { No }\end{array}$

later study involving more respondents (Vennix and Rouwette, 2000) is 0.82 , while reliability in the current study is 0.69 . For consensus, a scale developed by Vennix et al (1993) was used. Cronbach's alpha of a slightly adapted version of the scale is 0.84 (Vennix and Rouwette, 2000) and reliability in the current study, based on four items, is 0.60 . The final four items covered degree of shared vision, degree to which the model represented an integration of opinions, extent to which consensus was reached and closeness of opinions. Commitment is measured using a six-item scale developed by Dooley et al (2000). Cronbach's alpha in the original publication is 0.88 . In the present study, two items have a low correlation to the rest of the scale. After removing these two items, Cronbach's alpha is 0.56 , which we find acceptable. The final four items covered willingness to exert effort, pride on being involved in the project, degree to which project was beneficial to organization, degree to which respondent cared about decisions made.

Interviews followed a topic list, allowing interviewees to choose which subjects to discuss in more depth and to raise additional subjects. Questions on impacts on outcomes were asked in an open format (ie without mentioning the expected relation of intervention elements to outcomes). In each project at least one representative of the participating organizations was interviewed (see Table 1). We expect that this interview format allows participants with agendas not disclosed to other participants or to the facilitator to raise their concerns. Interviews were conducted, transcribed and analysed by a researcher not present in the modelling sessions (Bakker, 2008).
Transcriptions were analysed using a grounded theory approach (Hijmans and Peters, 2000). The text was broken up in scenes and codes were assigned to each scene. Filters were then used to connect codes to the three central outcomes. Filters selected by the researcher were, for instance, communication, commitment, consensus, facilitation and modelling. Relevant codes were connected to each filter. For example, in the communication filter at least one of the following codes was connected to a scene: communication, discussion, listening or projection. Data analysis was facilitated by using the software Kwalitan (Wester and Peters, 2004). An example of a section and scene coding is the following (translated from Dutch, codes are enclosed in [brackets]).

Researcher: in your opinion, are there any differences between normal meetings and this way of working?

Interviewee: the fact that the process and process modeling are the starting point. And that with numbers one tries to get a good idea of that ... [numbers]. I think this is a method which works well. A difficult part is the assumptions [assumptions] you always have to make. It is striking how easily the report has led to real changes and resources were made available [implementation].

Researcher: and how would you explain that?

Interviewee: I think the result is a good report [report]. And that it has been made by an independent institute ... If you leave this to one of the parties involved, it will have a particular overtone [neutrality]. You now have the feeling that the results are well-founded. It is a story with a firm basis that also clearly focuses on costs and benefits. Those are made very clear [foundation results]. 


\section{Results of the three cases}

In this section the results of the three cases are analysed. First, the meaning of communication, consensus and commitment in interviewees' own terms is described and compared to the definitions and scales used. Second, the change in outcomes as measured by both approaches is compared. Finally, the interview results are used to determine the influence of the intervention on outcomes.

\section{Meaning of outcomes}

In the interviews, participants were asked to indicate their understanding of the outcomes in their own words. With regard to communication, interviewees mentioned two aspects: room to discuss subjects that seemed relevant and focused listening by other participants and the facilitator. If we compare this to the five dimensions of communication described by Akkermans and Vennix (1997), we see that exchange of ideas/viewpoints, openness and freedom can be recognized in interviewees' comments. Common language and (lack of) verbal dominance are not mentioned. The interviews indicate that participants take consensus to refer to agreement between people on the model, assumptions in the model and results of the project. (Assumptions are model elements that are not explicitly supported by data, but require a best estimate by one or more of the participants.) Three aspects of consensus distinguished by Markóczy (2001) can be recognized: locus, scope and content. The fourth aspect, degree of consensus, is not mentioned. Interviewees provide more detail on the specific content to which consensus refers: assumptions, the model and conclusions. Three aspects of commitment are mentioned in the interviews: support for conclusions, the willingness to work with results and use project results in the participant's organization, and being involved with or connected to the team. These three aspects are very similar to Dooley et al's (2000) dimensions of acceptance of team goals and values, willingness to exert effort and desire to maintain membership. Interviewees focus more on carrying results forward than on maintaining membership of the team. As participants in a facilitated modelling project form a temporary team that will dissolve after the model and analysis are complete, this seems logical. In conclusion, two aspects of the definition of communication (common language and dominance) are not mentioned by participants, and specific dimensions of consensus and commitment are elaborated. Overall, the terms interviewees use to describe outcomes bear a strong resemblance to the dimensions used in the literature.

\section{Changes in outcomes}

The next question is to what extent communication, consensus and commitment have been created in these
Table 2 Outcomes aggregated over three cases

\begin{tabular}{lccccc}
\hline & $n$ & Minimum & Maximum & Mean & $S D$ \\
\hline Communication & 20 & 2.67 & 5.00 & 3.78 & 0.50 \\
Consensus & 20 & 2.50 & 4.75 & 4.03 & 0.50 \\
Commitment & 20 & 3.25 & 5.00 & 4.18 & 0.46 \\
\hline
\end{tabular}

Scales from 1: strongly disagree to 5 : strongly agree

three projects. The results of the questionnaires on outcomes are depicted in Table 2.

A Kolmogorov-Smirnov test shows that scores on the questionnaires are normally distributed. For each scale, the mean score of items over the three projects is calculated. A mean score higher than neutral indicates that participants feel the projects have contributed to the creation of communication, consensus and commitment. Means for items in each scale are significantly different from neutral $(t$-test 2 -tailed significance $<0.000)$. These results indicate that the three cases resulted in positive effects on outcomes. The interview results in general also point to positive outcomes, with one exception. Three participants in the third case indicated in the questionnaire that they feel commitment has been created. In the interviews, they pointed out that they did not really feel committed to the project, although they did feel a degree of support for the conclusions. This may point to a difference in interpretation of commitment: the more general commitment to the project versus more specific support for the conclusions. With the exception of these three scores on commitment, questionnaire and interview results are congruent.

\section{Relation of intervention to outcomes}

Finally, the interview results were used to analyse the relation of intervention elements to outcomes. Table 3 captures elements that according to interviewees contributed either positively or negatively to outcomes.

The interviews point to several impacts of the intervention on communication. The discussions were focused and participants felt they could make a contribution. The impact of contributions was clear. Other comments point to preferences with regard to communication content and form. We can see some support for the expected impacts in the literature (Franco, 2006; Rouwette et al, 2009). Participants find that information exchanged is easy to comprehend and that the intervention enabled them to process this information. The interviewees' comments on model assumptions seem to refer to legitimacy and accurateness of information. Sincerity could, to some extent, be related to paying attention to what participants say. In addition, participants value the focus in the discussions, and the fact that over the course of the intervention the joint process of the modelling team has been tough makes it easier to discuss irritations. 
Table 3 Relation of intervention to outcomes

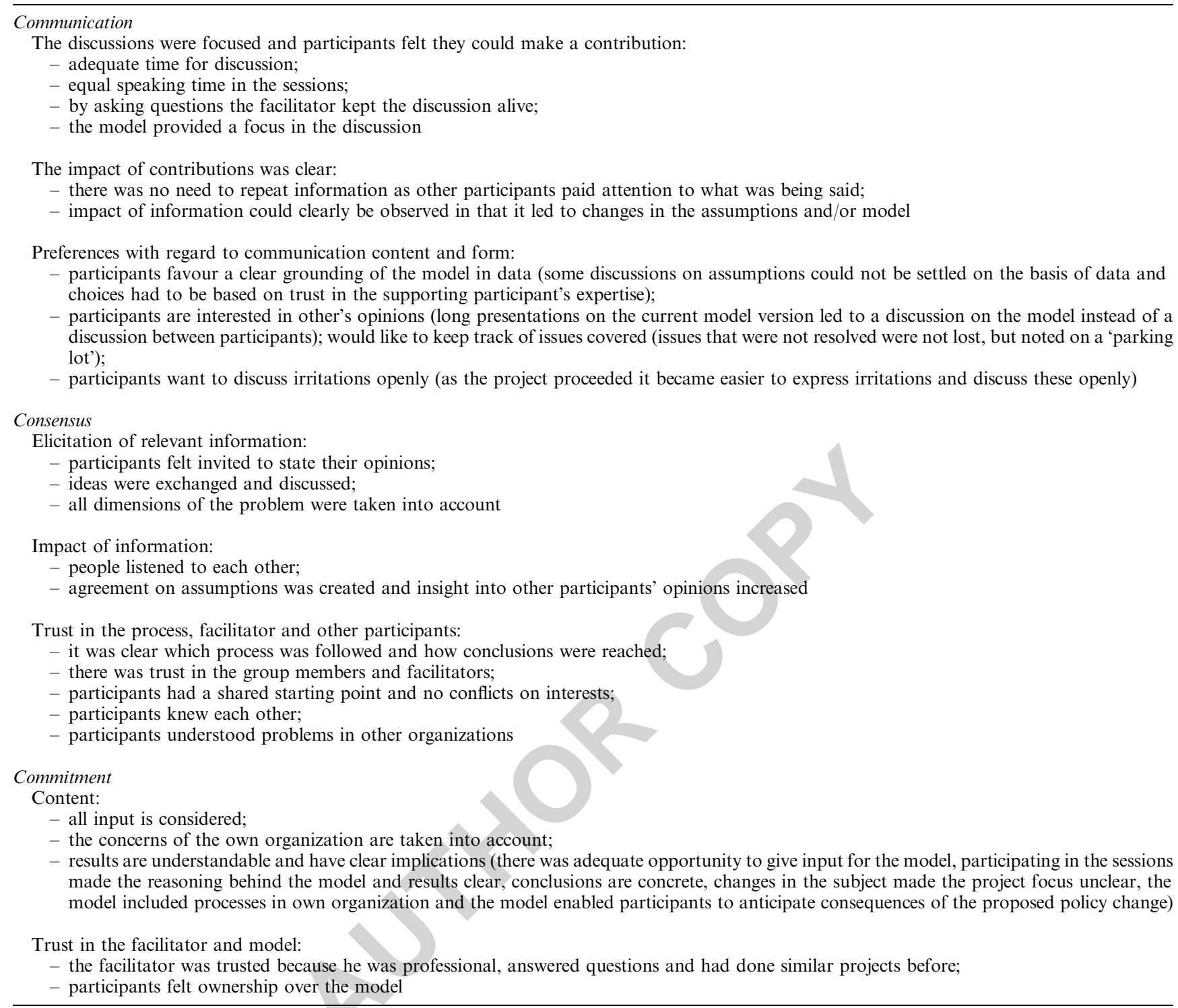

The impact of the intervention on consensus centres on eliciting relevant information and the impact of information. Other comments focus on trust in the process, facilitator and other participants. The impact on consensus proposed in the literature can be recognized to some extent. Information is exchanged and agreement is created (Rouwette et al, 2009). The model is not explicitly mentioned as an aid (transitional object) to clarify ideas, but the general process does contribute to the clarification of ideas (Eden and Ackerman, 2004).

The interviewees' assessment of the impact on commitment clearly shows a dimension related to content and trust. Trust in the facilitator and model is considered important. The proposed relations in the literature can be recognized. Co-construction of the model and ownership are clearly important (Akkermans and Vennix, 1997). The need to know the reasoning behind the model in order to feel committed seems close to the fairness of the procedure (Eden, 1992; Korsgaard et al, 1995; Eden and Ackermann, 1998).

\section{Conclusions and discussion}

Researchers in the field of strategic practice call for increased attention to technologies for strategy making, detailed analysis of how what strategists do constructs particular outcomes and explanations of variations in 
outcomes. Facilitated modelling, as one particular technology for supporting strategic decision making, focuses on increasing procedural rationality. Practitioners and researchers alike have pointed to a lack of systematic evaluation of results of facilitated modelling. This paper contributes to these research goals by developing more precise and useful measurements. Expectations were formulated on how mechanism (intervention) elements contribute to communication, consensus and commitment. These expectations were then researched in a three-group model building projects on strategic issues in a multiorganizational public policy setting. Data were gathered using measurement scales developed in the strategic management and decision support literature and semistructured interviews. Interviews allowed project participants to capture outcomes in their own words and relate these to elements of the intervention. Interviewees' interpretation of communication, consensus and commitment was in line with dimensions of these concepts as reported in the literature: two dimensions of communication were not mentioned in the interviews and specific dimensions of consensus and commitment were addressed in more detail by participants. The scores on the questionnaires were also similar to interview results to a great extent (only on one outcome, commitment, three out of 19 interviewees report a difference to the results in the questionnaires). On the basis of these three cases, there seems to be little reason in this instance for the concern that interviews and questionnaires do not always lead to the same conclusion (Eden, 2000). Finally, an attempt was made to explicitly relate intervention elements to outcomes, by comparing relations formulated in the literature to interview results. Interview results do not contradict the relations proposed in the literature and point out which elements of facilitated modelling are particularly effective.

These results clearly support the use of questionnaires in addition to other measurement methods such as in-depth interviews, observation or content analysis of project material. In this study, questionnaire scales developed by Vennix et al (1993) and Dooley et al (2000) were used. This paper emphasized how the facilitated modelling field may benefit from a clear definition of central concepts and precise measurements. Further development and testing in additional facilitated modelling projects is obviously needed. The cases in this study are restricted in the sense that they all involve multi-organizational and temporary team, working on strategic issues in public policy. No great differences in values or proposed directions were evident in these cases. We expected that participants would raise issues with regard to individual agendas not disclosed in the sessions, but a case on a more contentious issue would be a better test of this proposition. Participants in the cases will not directly implement the conclusions, which led to the choice of commitment to the decision-making team as an outcome measure here. Other ways of conceptualizing commitment may be used. Vennix et al (1993), for instance, refer to commitment as a perceived obligation to carry out a particular behaviour.

What seems clear is that questionnaires can make a contribution to more systematic assessment of projects and accumulation of research results, without losing the realism of real-life projects such as, for instance, hidden agendas. In the future this will hopefully allow the field to advance beyond anecdotal evidence and exploratory studies. Additional studies, in different contexts and using different mechanisms, may increase our insight into the robustness of results. A major topic for future studies is to assess the contribution of intervention elements to outcomes. We referred to research indicating that people have little insight into whether they have learned and what caused learning (Nisbett and Wilson, 1977; Wilson, 2002) and expected that the same may apply to changes in consensus and commitment. In the light of these conclusions, two steps seem important in determining the contribution of intervention elements to outcomes. First, we need to realize that the questionnaires employed in this study are based on participants' self-assessment after the intervention has taken place. A comparison to alternative ways of assessing outcomes can test how accurate post-test self-assessments of communication and consensus are. Rouwette et al (2009) describe alternative ways of measurement, which are, for instance, based on comparing belief structures before and after the intervention. This approach is relevant to the wider strategy field, since existing measurements of, for instance, commitment are based on post-test self-assessments (Dooley et al, 2000). Second, once an accurate assessment of outcomes has been identified, we need to avoid the trap of asking participants directly to what extent (elements of) the intervention contributed to an outcome. Clearly this is a question participants cannot answer. By developing measures for mechanism elements (for instance ability to process information or procedural fairness) and relating these to outcomes, participants' and facilitators' ideas on causes of changes could be tested.

\section{References}

Ackermann F, Eden C and Brown I (2005). The Practice of Making Strategy. A Step-by-Step Guide. Sage: London.

Akkermans H and Vennix J (1997). Clients' opinions on group model building: An exploratory study. Syst Dyn Rev 13(1): 3-31.

Andersen DF, Vennix JAM, Richardson GP and Rouwette EAJA (2007). Group model building: Problem structuring, policy simulation and decision support. J Opl Res Soc 58: 691-694.

Bakker S (2008). Creating Consensus and Commitment through Group Model Building. Radboud University Nijmegen: Nijmegen.

Checkland P (1989). Soft systems methodology. In: Rosenhead J (ed). Rational Analysis for a Problematic World. Wiley: Chichester, pp 71-100.

Checkland P (2000). Soft systems methodology: A thirty year retrospective. Syst Res Behav Sci 17: 11-58. 
DeStephen R and Hirokawa R (1988). Small group consensus. Stability of group support of the decision, task process, and group relationships. Small Group Behav 19: 227-239.

Dooley R, Fryxell G and Judge W (2000). Belaboring the not-soobvious: Consensus, commitment, and strategy implementation speed and success. J Mngt 26: 1237-1257.

Eden C (1989). Using cognitive mapping for strategic options development. In: Rosenhead J (ed). Rational Analysis for a Problematic World. Wiley: Chichester, pp 21-42.

Eden C (1992). A framework for thinking about group decision support systems (GDSS). Group Decis Negot 1: 199-218.

Eden C (1995). On evaluating the performance of 'wide-band' GDSS's. Eur J Opl Res 81: 302-311.

Eden C (2000). On evaluating the performance of GSS: Furthering the debate, by Paul Finlay (European Journal of Operational Research 107, pp 193-201). Eur J Opl Res 81: 218-222.

Eden C and Ackerman F (2004). Use of 'Soft OR' methods by clients, what do they want from them? In: Pidd M (ed). Systems Modelling: Theory and Practice. Wiley: Chichester, pp 146-163.

Eden C and Ackermann F (1998). Making Strategy. The Journey of Strategic Management. Sage: London.

Eden C and Ackermann F (2006). Where next for problem structuring methods. J Opl Res Soc 57: 766-768.

Eisenhardt KM and Zbaracki MJ (1997). Strategic decision making. Strategic Mngt J 13: 17-37.

Finlay P (1998). On evaluating the performance of GSS: Furthering the debate. Eur J Opl Res 81: 193-201.

Franco L (2006). Forms of conversation and problem structuring methods: A conceptual development. J Opl Res Soc 57: 813-821.

Franco L (2007). Assessing the impact of problem structuring methods in multi-organizational settings: An empirical investigation. J Opl Res Soc 58: 760-768.

Friend J (2001). The strategic choice approach. In: Rosenhead J and Mingers J (eds). Rational Analysis for a Problematic World Revisited. Problem Structuring Methods for Complexity, Uncertainty and Conflict. Wiley: Chichester, pp 115-149.

Friend J and Hickling A (1987). Planning Under Pressure. The Strategic Choice Approach. Pergamon Press: Oxford.

Gary M, Kunc M, Morecroft J and Rockart S (2009). System dynamics and strategy. Syst Dyn Rev 24: 407-429.

Hijmans E and Peters V (2000). Grounded theory in media research and the use of the computer. Communications 25: 407-432.

Jarzabkowski P and Spee A (2009). Strategy-as-practice: A review and future directions for the field. Int J Mngt Rev 11(1): 69-95.

Kellermanns F, Walter J, Lechner C and Floyd S (2005). The lack of consensus about strategic consensus: Advancing theory and research. J Mngt 31: 719-737.

Korsgaard M, Schweiger D and Sapienza H (1995). Building commitment, attachment, and trust in strategic decision making teams: The role of procedural justice. Acad Mngt J 38: 60-84.

Malhotra N and Birks D (2000). Marketing Research: An Applied Approach. Pearson Education Limited: Harlow.

Markóczy L (2001). Consensus formation during strategic change. Strategic Mngt J 22: 1013-1031.

Mason O and Mitroff I (1981). Challenging Strategic Planning Assumptions: Theory, Cases and Techniques. Wiley: New York.

McGrath JE (1982). Dilemmatics. The study of research choices and dilemmas. In: McGrath JE, Martin J and Kulka RA (eds). Judgment Calls in Research. Sage: Beverly Hills, pp 69-102.

Mingers J (2000). Variety is the spice of life: Combining soft and hard OR/MS methods. Int Trans Opl Res 7: 673-691.

Mingers J and Rosenhead J (2004). Problem structuring methods in action. Eur J Opl Res 152: 530-554.
Mintzberg H (1994). The Rise and Fall of Strategic Planning. Prentice-Hall: New York.

Morton A, Ackermann F and Belton V (2003). Technology-driven and model-driven approaches to group decision support: Focus, research philosophy, and key concepts. Eur J Inform Syst 12: 110-126.

Mowday R, Steers R and Porter L (1979). The measurement of organizational commitment. J Vocat Behav 14: 224-247.

Nisbett R and Wilson T (1977). Telling more than we can know: Verbal reports on mental processes. Psychol Rev 84: 231-259.

Pawson R and Tilley N (1997). Realistic Evaluation. Sage: London.

Pidd M (2004). Contemporary OR/MS in strategy development and policy-making: Some reflections. J Opl Res Soc 55: 791-800.

Poole MS and Folger JP (1981). Modes of observation and the validation of interaction analysis schemes. Small Group Behav 12: 477-493.

Richardson G, Andersen D, Maxwell T and Stewart T (1994). Foundations of mental model research. Paper presented at the ISDC 1994, Sterling, Scotland.

Rosenhead J (1996). What's the problem? An introduction to problem structuring methods. Interfaces 26(6): 117-131.

Rosenhead J and Mingers J (2001). Rational Analysis for a Problematic World Revisited. Problem Structuring Methods for Complexity, Uncertainty and Conflict. Wiley: Chichester.

Rouwette EAJA and Vennix JAM (2007). Team learning on messy problems. In: London $\mathrm{M}$ and Sessa V (eds). Work Group Learning: Understanding, Improving \& Assessing how Groups Learn in Organizations. Lawrence Erlbaum Associates: Mahwah, NJ, pp 243-284.

Rouwette EAJA, Vennix JAM and Felling AJA (2009). On evaluating the performance of problem structuring methods: An attempt at formulating a conceptual model. Group Decis Negot 18: 567-587.

Rouwette EAJA, Vennix JAM and Van Mullekom T (2002). Group model building effectiveness: A review of assessment studies. Syst Dyn Rev 18(1): 5-45.

Sanchez R and Heene A (2004). The New Strategic Management, Organization, Competition and Competence. John Wiley and Sons: New York.

Vennix J (1996). Group Model Building. Facilitating team Learning Using System Dynamics. Wiley: Chichester.

Vennix J, Scheper W and Willems R (1993). Group model building. What does the client think of it? In: Zepeda E and Machuca JAD (eds). Proceedings of the 1993 International System Dynamics Conference. System Dynamics Society: Albany, NY, pp 534-543.

Vennix JAM and Rouwette EAJA (2000). Group model building. What does the client think of it now? Paper presented at the International System Dynamics Conference, Bergen, Norway.

Warren K (2008). Strategic Management Dynamics. Wiley: Chichester.

Westcombe M, Franco L and Shaw D (2006). Where next for PSMs-A grassroots revolution? J Opl Res Soc 57: 776-778.

Wester F and Peters V (2004). Kwalitatieve Analyse. Uitgangspunten en Procedures. [Qualitative analysis. Fundamentals and procedures.] Coutinho: Bussum.

Wilson T (2002). Strangers to Ourselves, Discovering the Adaptive Unconsciousness. Harvard University Press: Cambridge, MA.

Received March 2009; accepted March 2010 after one revision 